\title{
Regional differences in awareness and attitudes regarding genetic testing for disease risk and ancestry
}

\author{
Charles R. Jonassaint $\cdot$ Eunice R. Santos $\cdot$ Crystal M. Glover • \\ Perry W. Payne $\cdot$ Grace-Ann Fasaye $\cdot$ Nefertiti Oji-Njideka $\cdot$ Stanley Hooker $\cdot$ \\ Wenndy Hernandez $\cdot$ Morris W. Foster $\cdot$ Rick A. Kittles $\cdot$ Charmaine D. Royal
}

Received: 22 February 2010/Accepted: 1 June 2010/Published online: 13 June 2010

(C) The Author(s) 2010. This article is published with open access at Springerlink.com

\begin{abstract}
Little is known about the lay public's awareness and attitudes concerning genetic testing and what factors influence their perspectives. The existing literature focuses mainly on ethnic and socioeconomic differences; however, here we focus on how awareness and attitudes regarding genetic testing differ by geographical regions in the US. We compared awareness and attitudes concerning genetic testing for disease risk and ancestry among 452 adults ( $41 \%$ Black and $67 \%$ female) in four major US cities, Norman, OK; Cincinnati, OH; Harlem, NY; and Washington, DC; prior to their participation in genetic
\end{abstract}

Although the terms 'race' and 'racial' are used in this manuscript, this does not mean that the authors subscribe to the view that the human species substructures into biological races. 'Race' is used because of its common and colloquial (though inappropriate) usage in United States (US) social and government parlance, and its presence in the relevant literature.

\section{R. Jonassaint · C. D. Royal ( $\square)$}

Institute for Genome Sciences \& Policy, Duke University, LSRC B-Wing, Room 320B, 450 Research Drive,

Box 91009, Durham, NC 27708, USA

e-mail: charmaine.royal@duke.edu

\section{E. R. Santos}

Division of Health Promotion and Behavioral Science,

University of Texas School of Public Health,

Houston, TX 77225, USA

\section{M. Glover}

Dartmouth Psychiatric Research Center, Dartmouth College, Concord, NH 03301, USA

\section{P. W. Payne}

Department of Clinical Research and Leadership, School of Public Health and Health Services, George Washington University School of Medicine and Health Sciences, Washington DC 20037, USA ancestry testing. The OK participants reported more detail about their personal ancestries $(p=0.02)$ and valued ancestry testing over disease testing more than all other sites $(p<0.01)$. The NY participants were more likely than other sites to seek genetic testing for disease $(p=0.01)$ and to see benefit in finding out more about one's ancestry $(p=0.02)$, while the DC participants reported reading and hearing more about genetic testing for African ancestry than all other sites $(p<0.01)$. These site differences were not better accounted for by sex, age, education, self-reported ethnicity, religion, or previous experience with genetic testing/counseling. Regional differences in awareness and attitudes transcend traditional demographic predictors, such as ethnicity, age and education. Local sociocultural factors, more than ethnicity and socioeconomic status, may influence the public's awareness and belief systems, particularly with respect to genetics.

\section{P. W. Payne}

Department of Health Policy, School of Public Health and Health Services, George Washington University School of Medicine and Health Sciences, Washington DC 20037, USA

G.-A. Fasaye

Inova Health System, Falls Church, VA 22042, USA

N. Oji-Njideka $\cdot$ S. Hooker $\cdot$ W. Hernandez $\cdot$ R. A. Kittles Section of Genetic Medicine, Department of Medicine, University of Chicago, Chicago, IL 60637, USA

M. W. Foster

Department of Anthropology, University of Oklahoma, Norman, OK 73019, USA

C. D. Royal

Department of African and African American Studies, Duke University, Durham, NC 27708, USA 


\section{Introduction}

The molecular revolution has brought about scientific advances that have increased the accessibility and use of genetic testing. Indeed, the need to disentangle questions about the public's understanding of and attitudes toward genetic testing has become more prominent (Condit 2001; Khoury et al. 2009). As genetic testing for disease risk, and now ancestry, become more popular, accessible, and more widely used, it is even more important to understand the cultural and demographic differences that may influence people's perceived personal utility of the science.

Since the Human Genome Project, the rate of identification of genes and genetic variants associated with various diseases has increased substantially, and is accompanied by a similar rate of development of genetic tests to identify persons at increased risk for those diseases (Guttmacher and Collins 2005). The incorporation of genetic testing into clinical care provides clinicians and the public with additional insight into familial and individual predisposition to certain diseases, allowing them to take additional steps to reduce those risks (Collins and McKusick 2001; Kaphingst and Mcbride 2010). However, there have also been anxieties regarding the potential misuse of genetic test results, such as marginalization and insurance or employment discrimination (Suther and Kiros 2009; Thompson et al. 2003; Wong et al. 2004). For personal genomics to be effective, education for the public and medical providers will need to keep up with the rapid pace of discovery in the field of genomic medicine (Khoury et al. 2009).

In recent years, direct-to-consumer (DTC) marketing of genetic tests for a host of diseases and various non-disease traits has become commonplace, allowing the public to have ready access to personal genetic and genomic information outside of the clinical setting (Lee and Crawley 2009; McCabe and McCabe 2004). While there are advocates of DTC testing for disease who highlight the potential for consumers to have more control and empowerment through access to their genetic information (Prainsack et al. 2008), some fear that consumers can be misled by commercial test results due to a lack of appropriate information, context, and counseling associated with the testing services (Bandelt et al. 2008; Hudson et al. 2007). Consumers frequently believe they are receiving valuable medical advice or diagnostic information (McGuire et al. 2009) while small print disclaimers on DTC genetic testing companies' websites typically state that their services $d o$ not offer medical advice, diagnosis or treatment (Howard and Borry 2009). Having an educational and informative discussion concerning the actual pros and cons of predictive genetic testing may dissuade initially interested individuals from pursuing genetic testing (Wilde et al. 2010). Thus, public education and ensuring potential consumers understand fully the risks, as well as the benefits of DTC genetic testing is of upmost importance.

Genetic ancestry estimation, another application of DTC testing, has also attracted public interest and demand, particularly among groups such as African Americans, who have had comparably less success with traditional family genealogical records (Bolnick et al. 2007; Elliott and Brodwin 2002). The potential personal or communal benefits of genetic ancestry testing notwithstanding, there are concerns about potential negative psychological, social, ethical, and political consequences, and inadequate communication and understanding about the limitations of testing (Bolnick et al. 2007; Duster 2009; Elliott and Brodwin 2002; Shriver and Kittles 2004; Winston and Kittles 2005). These concerns have led some scholars to call for regulation of genetic ancestry testing (Lee et al. 2009). Wagner (2010), however, notes that there is a need for empirical data on the actual impact of ancestry testing, since much of the existing literature on the topic is speculative.

In a qualitative study of genetic ancestry test-takers, Nelson (2008) found that for some, learning about their genetic ancestry overturned well-established beliefs about their identity, whereas for others, the information offered confirmation about their ancestry. However, there is not enough data to fully understand how consumers view genetic ancestry testing, how they interpret their test results, or the extent to which the results affect their psychological and social well-being. The psychosocial impact of the test results seems to be related to people's motivations for and preconceived notions of testing (Bolnick et al. 2007; Elliott and Brodwin 2002; Shriver and Kittles 2004; Winston and Kittles 2005). Thus, ascertaining people's perceptions of and attitudes towards genetic testing may be important in determining and addressing the effects test results may have.

Educational level has been thought to influence awareness and attitudes regarding genetic testing. In general, the public is not well informed about genetics, and although better-educated groups appear to be more knowledgeable (MacNew et al. 2010; Priest 2000), it has been difficult to attribute a person's perception that there are disadvantages to genetic testing to his or her educational level. Previous studies have shown that both lower (Gaskell et al. 1999; Thompson et al. 2003) and higher levels (Gaskell et al. 2000) of education are associated with negative perspectives on genetic testing, while other studies showed no association of education with attitudes or awareness (Einsiedel 2000; Hughes et al. 1997). Further, other evidence suggests that educational background does influence how much information or perceived benefit an individual might gain from advertisements and educational material on genetic testing (Bowen et al. 2009); which in turn, may 
influence participation in genetic testing. As some research suggests, those from higher education neighborhoods are more likely to participate in genetic testing for disease (Hensley Alford et al. 2010). Overall, whatever the mechanism, the influence of educational level on attitudes towards genetic testing is unclear, and previous associations are likely due to other sociodemographic factors that are correlated with education level.

In contrast to the unclear association between education and attitudes towards genetic testing, there have been consistent findings concerning the relationship between race or ethnicity and attitudes and awareness regarding testing. In general, minority ethnic groups report lower knowledge and greater concern regarding genetic testing (Singer et al. 2004; Suther and Kiros 2009) and are less accepting of genetic testing than their White counterparts (Armstrong et al. 2005; Case et al. 2007; Halbert et al. 2006; Hughes et al. 1997; Peters et al. 2004). This is not surprising given the well-documented mistreatment of minorities in medical research in the past (Fairchild and Bayer 1999; Gamble 1993, 1997), and the African American community's expressed mistrust of medical research (Corbie-Smith et al. 1999) and genetic testing (Suther and Kiros 2009; Thompson et al. 2003). In addition, there are significant racial differences in cultural values (Halbert et al. 2007) and awareness regarding genetic testing (MacNew et al. 2010) that may influence an individual's perception of medical research including genetics. Given the current attention to racial/ethnic health disparities and mounting findings showing genetic variants associated with heightened disease risk or particular treatment responses that differ significantly in frequency among racial/ethnic groups (Ge et al. 2009; Zeigler-Johnson et al. 2008; Zhang et al. 2009; Zhu et al. 2005), there will likely be increased interest in racial/ethnic differences in attitudes toward genetic testing.

Few studies have looked for regional differences in awareness and attitudes regarding genetic testing that may implicitly suggest influential sociocultural factors within each region, not specifically tied to educational background or race/ethnicity. One study examining regional differences showed that a lower percentage of Canadian participants than US participants indicated at least one negative emotional response to genetic testing for hemochromatosis (Power et al. 2007). Similarities in attitudes towards genetic testing have also been shown across people of different backgrounds within the same region. Westerners and non-Westerner immigrants in the Netherlands were shown to have similar attitudes towards genetic testing for cystic fibrosis (Lakeman et al. 2008, 2009).

Cities in the US can be drastically different from each other, particularly with regard to their culture, structure, climate, and concentration on education and research. Each major US city might have its own unique traditions, pastimes and differing social influences, each tending to have its own idiosyncrasies developed directly from the history of the given place, and its people. Much of the culture, molded by the economy and type of market that is most prevalent, becomes specialized over time, leading to more drastic regional differences over time (Scott 2000).

In summary, previous research has focused mostly on racial/ethnic and socioeconomic differences in attitudes towards genetic testing. It has been suggested that views differ mainly by racial/ethnic or socioeconomic status; however, less research has examined within group and regional differences. There may be more variability among people of different regions of the country than people of different race/ethnicity or socioeconomic strata. The goal of the current study is to evaluate differences in awareness and attitudes regarding genetic testing for disease and ancestry among and within four geographically diverse regions in the US; Norman, OK; Cincinnati, OH; Harlem, $\mathrm{NY}$; and Washington, DC.

\section{Methods}

\section{Study sample}

The sample consisted of 452 persons, 146 (32.3\%) males and $306(67.7 \%)$ females, with a mean age of 48.7 years (range 18-82, SD = 15.9) (Table 1). Approximately 66\% percent of participants reported that they were married, widowed, or separated/divorced, and about $32 \%$ were never married. Most of the participants $(88.94 \%)$ had at least some college education or were college graduates, and most (67.04\%) were employed. A large proportion of participants reported their ethnicity as African American (41.15\%); however, about $28 \%$ of participants failed to or chose not to report their ethnicity. All study participants were attendees at community forums on DNA testing for ancestry that were held in OK $(n=94), \mathrm{OH}(n=98), \mathrm{NY}$ $(n=153)$, and DC $(n=107)$.

\section{Recruitment and data collection procedures}

Participants were recruited through four community-based forums convened between June 2004 and March 2006 in Norman, OK; Cincinnati, OH; Harlem, NY; and Washington, DC. The forums were put together with the help of local host organizations and advertised through mass media, community organizations, churches, and flyers. Attendees came from across the respective states or metropolitan areas and have/had ongoing contact with the host sites. Information was not available on where participants grew up or how long they had been living in their 
Table 1 Sociodemographic characteristics of the sample

\begin{tabular}{|c|c|c|c|c|c|c|}
\hline \multirow[t]{2}{*}{ Variables } & \multicolumn{4}{|l|}{ Sites } & \multicolumn{2}{|c|}{ Total $(N=452)$} \\
\hline & OK (94) & $\mathrm{OH}(98)$ & NY (153) & DC (107) & $n$ & $\%$ \\
\hline \multicolumn{7}{|l|}{ Gender } \\
\hline Male & 36 & 27 & 47 & 36 & 146 & 32.30 \\
\hline Female & 58 & 71 & 106 & 71 & 306 & 67.70 \\
\hline \multicolumn{7}{|l|}{ Age* (years) } \\
\hline $18-35$ & 11 & 19 & 24 & 22 & 76 & 16.81 \\
\hline $36-50$ & 67 & 67 & 92 & 75 & 301 & 66.59 \\
\hline $51-65$ & 16 & 12 & 36 & 10 & 74 & 16.37 \\
\hline Missing data & 0 & 0 & 1 & 0 & 1 & 0.22 \\
\hline \multicolumn{7}{|l|}{ Ethnicity* } \\
\hline African American & 29 & 48 & 49 & 60 & 186 & 41.15 \\
\hline White & 7 & 10 & 22 & 1 & 40 & 8.85 \\
\hline Other & 6 & 6 & 18 & 14 & 44 & 9.73 \\
\hline Mixed & 27 & 3 & 20 & 7 & 57 & 12.61 \\
\hline Missing data & 26 & 31 & 44 & 24 & 125 & 27.65 \\
\hline \multicolumn{7}{|l|}{ Marital Stat. } \\
\hline Married & 44 & 39 & 55 & 35 & 173 & 38.27 \\
\hline Widowed & 8 & 5 & 15 & 2 & 30 & 6.64 \\
\hline Separated/divorced & 20 & 25 & 25 & 25 & 95 & 21.02 \\
\hline Never married & 22 & 25 & 56 & 42 & 145 & 32.08 \\
\hline Other & 0 & 4 & 2 & 3 & 9 & 1.99 \\
\hline \multicolumn{7}{|l|}{ Education* } \\
\hline$\leq$ High school & 15 & 8 & 20 & 6 & 49 & 10.84 \\
\hline$\leq$ College & 46 & 52 & 82 & 56 & 236 & 52.21 \\
\hline Graduate/professional & 33 & 38 & 50 & 45 & 166 & 36.73 \\
\hline Missing data & 0 & 0 & 1 & 0 & 1 & 0.22 \\
\hline \multicolumn{7}{|l|}{ Employ. Stat } \\
\hline Employed & 63 & 73 & 83 & 84 & 303 & 67.04 \\
\hline Not employed & 6 & 4 & 22 & 6 & 38 & 8.41 \\
\hline Retired & 24 & 21 & 48 & 17 & 110 & 24.34 \\
\hline Missing data & 1 & 0 & 0 & 0 & 1 & 0.22 \\
\hline \multicolumn{7}{|l|}{ Job } \\
\hline Student/other & 4 & 4 & 5 & 1 & 14 & 3.10 \\
\hline Unskilled & 5 & 3 & 12 & 2 & 22 & 4.87 \\
\hline Skilled & 27 & 21 & 36 & 32 & 116 & 25.66 \\
\hline Professional & 45 & 58 & 79 & 61 & 243 & 53.76 \\
\hline Missing data & 13 & 12 & 21 & 11 & 57 & 12.61 \\
\hline \multicolumn{7}{|l|}{ Income } \\
\hline Less than $\$ 25,000$ & 21 & 16 & 30 & 14 & 81 & 17.92 \\
\hline$\$ 25,000-49,000$ & 28 & 24 & 33 & 27 & 112 & 24.78 \\
\hline$\$ 50,000-99,000$ & 28 & 32 & 33 & 39 & 132 & 29.20 \\
\hline At least $\$ 100,000$ & 9 & 9 & 21 & 18 & 57 & 12.61 \\
\hline Missing data & 8 & 17 & 36 & 9 & 70 & 15.49 \\
\hline \multicolumn{7}{|l|}{ Religion* } \\
\hline Christian & 78 & 79 & 123 & 74 & 354 & 78.67 \\
\hline Other & 10 & 13 & 23 & 17 & 63 & 14.00 \\
\hline None & 4 & 5 & 7 & 17 & 33 & 7.33 \\
\hline
\end{tabular}

Three participants, one from $\mathrm{OH}, \mathrm{NY}$ and DC, were missing data on all demographic variables and were not included in the analyses of site differences in demographic variables

* Significant difference between groups for the variable $(p<0.05)$ 
current location. The primary purpose of the forums was to provide information on genetic ancestry testing and respond to questions from community members. There was also some discussion of genetics and disease. Potential attendees were informed beforehand that free genetic testing would be offered and that the present study on attitudes toward genetic testing would be conducted. Virtually all attendees participated in both genetic ancestry testing and this study. This paper describes awareness and attitudes of study participants prior to their uptake of genetic ancestry testing. Study goals and procedures were explained to participants, after which they received two copies of the consent form, one to sign and return and the other to keep for their records. Participants then completed a 22-item survey eliciting information on their background, knowledge about their ancestry, awareness and value of genetic testing for disease and ancestry, perceived benefits and risks of genetic ancestry testing, and motivations for having ancestry testing. The survey was self-administered and comprised both fixed-choice and open-ended items. Knowledge about personal ancestry was determined by quantifying the amount of detail the participant reported in response to an open-ended question asking, "How much do you know about your ancestry in general?" Approval for the study was obtained from the Institutional Review Board at Howard University.

\section{Data analysis}

Chi-square tests were performed to analyze site differences on categorical variables. Fisher's exact test $p$ values are reported for comparisons where cell sizes are less than 5 . Significant chi-square tests were followed by logistic regressions. Variables were recoded for logistic regression analyses in that the response choice of interest was coded as ' 1 ' and all other responses were coded as ' 0 '. ANOVA tests were performed to examine site differences on continuous variables. All multivariate tests (i.e. logistic regressions and ANOVAs) controlled for sex, age, and education. Self-reported ethnicity was not used as a covariate due to the significant frequency of missing responses $(28 \%)$. All data analyses were performed using SAS 9.0.

\section{Results}

Site demographics

We looked at demographic factors to determine what characteristics among the four sites might relate to differences in knowledge, awareness and attitudes regarding genetic testing. Descriptive demographic data by site are presented in Table 1. A significant chi-square test showed differences in reported ethnicity among sites in that both the $\mathrm{OH}$ and DC sites had greater percentages of participants reporting African American ethnicity, 73.4 and $76.9 \%$, respectively, than the OK site, $42.6 \%$, and the NY site, $45.0 \%(p<0.001)$. Further, the OK site had a significantly larger percentage of self-reported mixed ethnicity participants, $39.7 \%$, than the other three sites, $<18.4 \%$, $p<0.05$. Over $28 \%$ of participants failed to report their ethnicity. There were no site differences in participants' tendency to not report their ethnicity. For age, the DC site was younger than both the $\mathrm{OK}$ and $\mathrm{OH}$ sites $(p=0.043)$, and for education, the DC and $\mathrm{OH}$ site had a higher education level than both the OK and NY sites $(p=0.036)$. The NY site had the largest percentage of unemployed participants, 9.9 compared to $4.0 \%$ on average for all other sites $(p=0.014)$. For religion, of all four sites, the DC group had the largest proportion of participants reporting "no religion" (15.7 vs. $\leq 5.15 \%)$ and the smallest proportion of participants identifying with Christianity (68.5 vs. $\geq 80.4 ; p=0.01$ ). In summary, the $\mathrm{OK}$ and NY sites had fewer self-reported African Americans, while the DC participants were younger, had a higher mean education, and were less likely to identify with an organized religion than all other sites. We considered these factors in later analyses as possible alternative explanations for site differences in awareness and attitudes.

\section{Experience and awareness}

As shown in Table 2, 15.0\% of all participants previously had genetic testing or counseling for disease risk. There were no site differences in past experience with genetic testing or counseling.

The DC site reported reading or hearing more about genetic testing for African ancestry than all other sites $(p<0.001)$, and knowing more about genetic testing in general than the $\mathrm{OH}$ site $(p<0.05$; Table 3$)$. However, with respect to knowledge about their personal ancestry, participants at the OK site reported more detail about their own personal ancestry than participants in either the $\mathrm{OH}$ or DC group $(p=0.02)$.

\section{Attitudes}

Participants from the NY site were more likely to request disease-related genetic testing $(76.8 \%)$ than participants at all other sites $(<65.4 \% ; p=0.014)$. In particular, the NY site was 2.5 times more likely to request genetic testing for disease than the OK site and about two times more likely than the $\mathrm{OH}$ and DC participants.

When asked, "How important is it to you to find out more about your ancestry?" the NY group was almost two 
Table 2 Experience and attitudes regarding genetic testing

\begin{tabular}{|c|c|c|c|c|c|c|}
\hline & OK & $\mathrm{OH}$ & NY & DC & Total & $p$ value \\
\hline \multicolumn{7}{|c|}{ Have you had previous genetic testing/counseling? } \\
\hline Yes $(\%)$ & $9(9.6)$ & $14(14.3)$ & $24(15.7)$ & $21(19.6)$ & $68(15.0)$ & \multirow[t]{3}{*}{0.381} \\
\hline No $(\%)$ & $81(86.2)$ & $83(84.7)$ & $123(80.4)$ & $82(76.6)$ & $369(81.7)$ & \\
\hline Unsure $(\%)$ & $4(4.3)$ & $1(1.0)$ & $6(3.9)$ & $4(3.7)$ & $15(3.3)$ & \\
\hline \multicolumn{7}{|c|}{ Would you request genetic testing for disease risk? } \\
\hline Yes $(\%)$ & $54(58.1)$ & $63(64.3)$ & $116(76.8)$ & $70(65.4)$ & $303(67.5)$ & \multirow[t]{3}{*}{0.014} \\
\hline No $(\%)$ & $19(20.4)$ & $12(12.2)$ & $8(5.3)$ & $15(14.0)$ & $54(12.0)$ & \\
\hline Unsure $(\%)$ & $20(21.5)$ & $23(23.5)$ & $27(17.9)$ & $22(20.5)$ & $92(20.5)$ & \\
\hline \multicolumn{7}{|c|}{ How important is it to you to find out more about your ancestry? } \\
\hline Not at all important (\%) & $2(2.1)$ & $1(1.0)$ & $2(1.3)$ & $1(0.9)$ & $6(1.3)$ & \multirow[t]{3}{*}{0.012} \\
\hline Somewhat important $(\%)$ & $16(17.0)$ & $29(29.9)$ & $17(11.2)$ & $21(19.4)$ & $83(18.4)$ & \\
\hline Very important $(\%)$ & $76(80.9)$ & $67(69.1)$ & $133(87.5)$ & $86(79.6)$ & $362(80.3)$ & \\
\hline \multicolumn{7}{|c|}{ Do you see possible benefits from having a DNA test for ancestry? } \\
\hline No $(\%)$ & $13(14.4)$ & $5(5.3)$ & $9(6.2)$ & $7(6.5)$ & $34(7.8)$ & \multirow[t]{2}{*}{0.066} \\
\hline Yes $(\%)$ & $77(85.6)$ & $90(94.7)$ & $137(93.8)$ & $100(93.5)$ & $404(92.2)$ & \\
\hline \multicolumn{7}{|c|}{ Do you see possible harms or risks from having a DNA test for ancestry? } \\
\hline No $(\%)$ & $75(81.5)$ & $86(88.7)$ & $125(85.0)$ & $90(84.1)$ & $376(84.9)$ & \multirow[t]{2}{*}{0.585} \\
\hline Yes $(\%)$ & $17(18.5)$ & $11(11.3)$ & $22(15.0)$ & $17(15.9)$ & $67(15.1)$ & \\
\hline \multicolumn{7}{|l|}{ Which do you value more personally? } \\
\hline Ancestry testing $(\%)$ & $34.0(37.0)$ & $10.0(10.5)$ & $26.0(17.8)$ & $29.0(26.9)$ & $99.0(22.4)$ & \multirow[t]{3}{*}{$<0.001$} \\
\hline Genetic testing for disease risk $(\%)$ & $3.0(3.3)$ & $15.0(15.8)$ & $3.0(2.1)$ & $9.0(8.3)$ & $30.0(6.8)$ & \\
\hline Both equally $(\%)$ & $55.0(59.8)$ & $70.0(73.7)$ & $117.0(80.1)$ & $70.0(64.8)$ & $312.0(70.7)$ & \\
\hline
\end{tabular}

Table 3 Awareness about genetic testing and knowledge about personal ancestry

\begin{tabular}{|c|c|c|c|c|c|}
\hline & $\begin{array}{l}\text { OK } \\
\text { Means (SE) }\end{array}$ & $\begin{array}{l}\mathrm{OH} \\
\text { Means (SE) }\end{array}$ & $\begin{array}{l}\text { NY } \\
\text { Means (SE) }\end{array}$ & $\begin{array}{l}\text { DC } \\
\text { Means (SE) }\end{array}$ & $p$ value \\
\hline $\begin{array}{l}\text { How much have you read or heard about genetic } \\
\text { (DNA) testing in general? }\end{array}$ & $4.47(0.18)$ & $4.18^{\mathrm{a}}(0.18)$ & $4.46(0.14)$ & $4.74^{\mathrm{b}}(0.17)$ & 0.169 \\
\hline $\begin{array}{l}\text { How much have you read or heard about genetic } \\
\text { testing for disease risk? }\end{array}$ & $4.09(0.19)$ & $4.01(0.19)$ & $4.15(0.15)$ & $4.11(0.18)$ & 0.984 \\
\hline $\begin{array}{l}\text { How much have you read or heard about genetic } \\
\text { testing for African ancestry? }\end{array}$ & $3.63(0.20)$ & $3.32(0.19)$ & $3.97(0.15)$ & $4.59 *(0.19)$ & $<0.001$ \\
\hline $\begin{array}{l}\text { How much do you know about your ancestry in general } \\
\text { (not only your African ancestry)? }\end{array}$ & $2.40^{\mathrm{a}}(0.09)$ & $2.16^{\mathrm{b}}(0.08)$ & $2.32(0.07)$ & $2.12^{\mathrm{b}}(0.08)$ & $<0.02$ \\
\hline
\end{tabular}

* Significantly different from all other groups $p=<0.01$

${ }^{\mathrm{a}}$ Significantly different from $^{\mathrm{b}}<0.05$

times more likely to indicate "very important" than the DC and OK groups, and was three times more likely to indicate "very important" than the $\mathrm{OH}$ group $(p=0.012$; Table 2). The OK group tended to see less benefit in genetic testing for ancestry than participants from other sites, but this association only approached significance $(p=0.06)$. It appears that overall the NY group had the most positive attitude toward genetic testing and the OK group had the least positive. Seventy percent of participants in the study valued both genetic testing for disease and ancestry equally. However, although the OK participants were least positive about both ancestry and disease testing than participants from the other three sites, they valued ancestry testing more than disease testing. In fact, OK participants were 2.6 and 4.7 times more likely to value ancestry testing over disease testing than the $\mathrm{OH}$ and NY sites, respectively $(p<0.001)$. We performed a sub-group analysis limiting the sample to individuals reporting any African ethnicity and found that the effect showing a preference for ancestry testing over disease testing among the OK group remained significant $(p=0.004)$. 
Table 4 Principal components items and loadings

\begin{tabular}{lrr}
\hline & Awareness & Attitude \\
\hline Would you request genetic testing for disease risk? & -0.05 & $0.53^{*}$ \\
Do you see possible benefits from having a DNA test for ancestry? & 0.03 & $-0.52^{*}$ \\
How important is it to you to find out more about your ancestry? & 0.02 & 0.09 \\
Do you see possible harms or risks from having a DNA test for ancestry? & $0.40^{*}$ & $0.38^{*}$ \\
How much have you read or heard about genetic (DNA) testing in general? (1-7) & $0.36^{*}$ & -0.03 \\
How much have you read or heard about genetic testing for disease risk? (1-7) & -0.06 \\
How much have you read or heard about genetic testing for African ancestry? (1-7)
\end{tabular}

Are site differences due to previous experience, ethnicity, or religion?

To determine whether the above site differences in awareness and attitudes were due to other variables, we reran each multivariate model and added separately the following variables as covariates: previous experience with genetic testing/counseling, self-reported ethnicity, and religion. If these variables explained the effect of site differences, when added to the model, site would no longer be significant or the effect of site would decrease. In each model, however, the site differences remained and were independent of all covariates. Thus, site differences in awareness and attitudes are independent of factors such as previous experiences and religion. It is difficult to determine whether self-reported ethnicity may explain these effects due to the significant amount of missing data on this variable. However, when limiting the sample to only those with available ethnicity data $(n=327)$, there were still significant site differences in attitudes and awareness; and, including ethnicity in the model did not attenuate these effects.

Principal components of attitudes and awareness

To help illustrate the findings of this study, the differences across the US in awareness and attitudes towards genetic testing, we ran a principal component analysis on participant responses to seven items that represent attitudes and awareness concerning genetic testing for disease and ancestry to identify principal components describing the most variation in the data. Table 4 shows items and loadings for the top two principal components which together explain $50 \%$ of the variance in participant responses; the first component representing awareness and the second representing attitudes towards testing. One item, "Do you see possible harms or risks from having a DNA test for ancestry?" did not load significantly on either component.

Figure 1 shows means for these top two components by site. The data plot of the two top principal components for each site suggests that examining the combinations of both

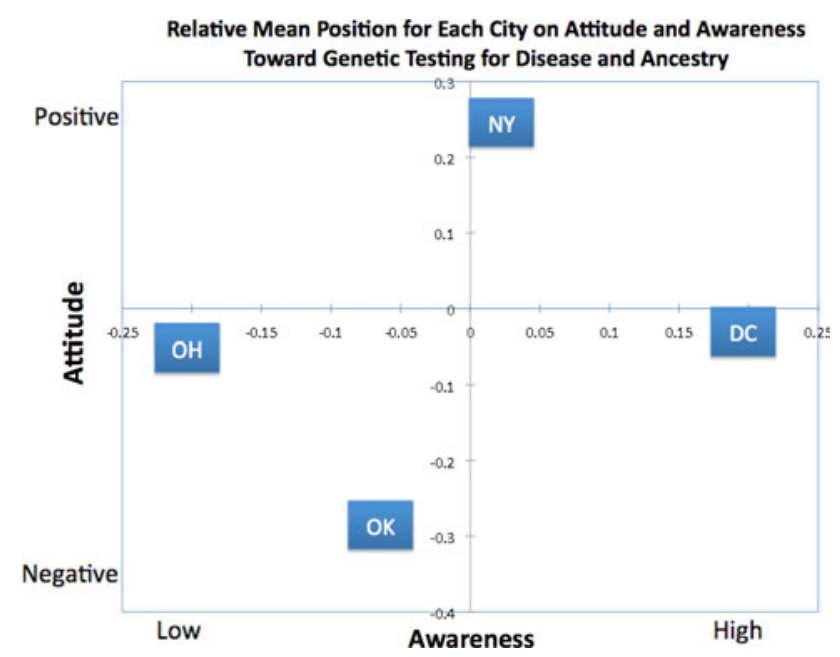

Fig. 1 Site differences in attitude and awareness factor scores

awareness and attitudes may reveal even more divergence between each site than was evident when looking at individual factors alone; regions are more clearly differentiated from each other in respect to awareness and attitudes. The DC participants expressed the highest awareness of genetic testing for disease and ancestry but were neutral in their attitudes. NY site participants expressed the most positive attitude towards testing while reporting only average awareness. The $\mathrm{OH}$ site reported being neutral in attitude and low in awareness, while the OK site reported the least positive attitude towards testing and below average awareness. These stark regional differences in attitudes and awareness could not be better explained by any other measured variable.

\section{Discussion}

The current study benefited from a sample that was socioeconomically, ethnically, and regionally diverse. Unlike research by Chen and Goodson (2007) that indicates associations between genetic testing attitudes and socioeconomic status, gender, and age, our findings show that 
differences in awareness and attitudes among four geographically diverse major cities in the US: Norman, OK; Cincinnati, OH; Harlem, NY; and Washington, DC, could not be better accounted for by demographic factors that have typically been associated with attitudes towards genetic testing. Findings from this study suggest that ethnicity alone does not determine an individual's socioenvironmental experience or beliefs about genetic testing. This paper presents a different perspective from previous studies that treated ethnic groups as monolithic and have suggested awareness, beliefs, and attitudes towards genetic testing for disease are largely driven by ethnicity (see Lannin et al. 1998; Lerman et al. 1999; Palmer et al. 2008; Suther and Kiros 2009). Instead, our findings point to awareness and attitude differences within ethnic groups and similarities across ethnic groups residing in the same region.

Although $28 \%$ of the participants chose to not report their ethnicity, the data that we do have indicates that our sample was ethnically diverse. Forty-two percent identified as African American, $9 \%$ as White, and 13\% as mixed. The remaining participants reported other ethnicities not broadly categorized (i.e. East African, West African, AfroCaribbean, Central American, Native American, or Central African). The preponderance of missing self-report ethnicity data in this study may reflect public attitudes towards genetic testing and/or race. Other variables that typically have a high frequency of non-response for surveys, such as income and occupation had lower levels of missing data (12 and 15\%, respectively) than self-reported ethnicity in the current study. Missing ethnicity data was not associated with education, SES, or geographic region. Participants were also asked to report the ethnicity of their parents and grandparents. Of those participants who did not report their own ethnicity, only $23 \%$ failed to report ethnicity for any of their grandparents, suggesting that participants were deliberate and may have had a variety of motivations underlying their pattern of reporting for ethnicity.

Participants may have chosen to not report their own ethnicity for several reasons including an uncertainty about their own ethnicity and fear of being wrong, perceived lack of privacy, and the potential for misuse and misinterpretation of this information. The use of race and ethnicity in the research and clinical settings has historically been problematic (Caulfield et al. 2009; Duster 2006). Given the current social context of racial profiling, growing inequities, and media hype, the potential harms associated with racial and ethnic categorization cannot be ignored (Varcoe et al. 2009). These issues might be associated with the reluctance of some participants to report their own ethnicity.

The sites used for the sample were geographically dispersed, with an average of 530 miles between each site and over 1,500 miles separating Norman, OK, from Harlem, NY. Thus the current study was well designed to identify possible regional differences in the lay public's awareness and attitudes regarding genetic testing for disease and ancestry, while also ruling out demographic factors that could logically account for these differences.

The Harlem, NY, group had the largest percentage of unemployed and the largest percentage of White participants. The NY group reported being more likely to request genetic testing for disease and placed the most importance on finding out more about their ancestry. Overall, the NY group had the most positive attitude towards genetic testing while reporting average awareness.

Harlem, NY, is traditionally a predominantly Black area that has experienced significant ethnic shifts due to economic boom and bust cycles (Taylor 1998). Being at the heart of NY, an international city, Harlem may be fully exposed to a culture of curiosity and openness to new ideas, thus promoting positive attitudes towards science and medicine.

The Washington, DC group was the youngest, had the largest percentage of African Americans, and had the largest proportion of participants with no religious affiliation. The DC site reported reading and hearing more about genetic testing for African ancestry and generally had more awareness of genetic testing than all other sites.

Washington, DC differs from all US cities because it was specifically established to serve as the nation's capital by the Constitution of the United States (United States National Park Service and Parks and History Association 1987). It has been embroiled in issues of politics, policy, race, and national identity from the very beginning (Taylor 1998). DC residents potentially have more exposure to genetic testing information due to the presence of a number of academic and policy institutions in the area and proximity to the National Institutes of Health, as well as media communications in DC surrounding the genetic testing discourse. Washington, DC is also home to a prominent genetic ancestry testing company (i.e., African Ancestry Inc.), which might partially account for the increased awareness among DC participants about genetic testing for African ancestry. Prior research suggesting that DTC advertising of genetic testing is positively associated with awareness of genetic testing (Bowen et al. 2009) supports this hypothesis.

The Cincinnati, $\mathrm{OH}$ group had a large percentage of African Americans and the smallest number of participants identifying as mixed. The $\mathrm{OH}$ group was least likely to indicate that finding out more about their ancestry was very important and generally reported the lowest level of awareness about genetic testing.

Cincinnati, $\mathrm{OH}$, is sometimes thought of as the first purely American city, lacking the heavy European influence that was present on the east coast (Taylor 1998). Race relations in Cincinnati have historically been tense as it lies 
at the intersection of states that allowed slavery before the Civil War, namely Kentucky, and one that did not, namely Ohio, as well as being an important stop on the Underground Railroad (Taylor 1998). Despite the highly racialized history of Cincinnati, however, ethnic identity did not seem to influence the pattern of responding among this group.

The Norman, OK group was the most ethnically diverse with almost $30 \%$ of the participants reporting mixed ethnicity. This may have been due to a high number of participants within the OK group that believed they had considerable Indigenous American ancestry. Accordingly, they reported more details about their personal ancestries than other sites.

Norman, OK, is approximately 20 miles south of downtown Oklahoma City. Among study sites Oklahoma is unique due to its Native American heritage (May 1996). It has the second largest population of Native Americans (United States Bureau of the Census Geography Division 2002) and more than 25 Native American languages are spoken in the state, the most of any state (King 2008).

The general reluctance of some Native Americans or Native American tribes to participate in genetic research and other genetics-related activities has been well discussed (Bolnick et al. 2007; International HapMap Consortium 2004; TallBear 2007) and supports most attitudinal findings from the OK participants in this study, many of whom claim some Native American ancestry. The OK site had below average awareness about genetic testing and expressed the least positive attitudes towards genetic testing, but, interestingly, valued ancestry testing more than disease testing. Their preference for ancestry testing might be due to the potential or expected material gains associated with having evidence of one's Native American ancestry.

Overall, whatever the factors underlying these regional differences, clear distinctions among the sites can be made in terms of awareness and attitudes regarding genetic testing that are surprisingly not better explained by demographic factors. Our interpretations of the outcomes are largely speculative; however, our explanations concerning findings for Washington, DC and Oklahoma are based on years of experience working with the participating communities and host organizations at those sites, as well as our unpublished data and observations of what ensued at the forums. Our study is an incremental step towards filling the gap in knowledge regarding differences in awareness and attitudes toward genetic testing in general and ancestry testing in particular. Further research will be needed to validate our findings and determine specific underlying factors.

The results from this study must be interpreted in the context of the following limitations. First, the unavailability of self-reported ethnicity for many participants compromised our ability to adequately explore the relationship of that variable to awareness and attitudes. Second, all study participants attended a forum on ancestry testing and volunteered for free genetic testing for ancestry, thus the sample is subject to selection bias. The sample is unlikely to be representative of the population. Most participants generally had positive views towards genetic testing, which is expected given that all participants voluntarily attended a forum on genetic testing for ancestry. Third, the Southern and Western regions of the country were not represented in the study. Their inclusion may have added to the present findings and resulted in larger and more informative regional differences. Despite these limitations, we argue that the additional ethnicity information as well as the inclusion of individuals who would not have attended a forum on genetic ancestry testing, individuals who did not receive genetic testing, and individuals from other geographic regions (e.g., Western and Southern states) might have only further strengthened our results by providing more variability in responses, and potentially further differentiating the sites. Our results provide insight from four cities and can (1) inform the development or refinement of a concept model of factors that are linked to genetic testing and (2) guide future studies seeking to explain why there are differences in awareness and attitudes regarding genetic testing.

In conclusion, we make a couple of recommendations for future research. First, research identifying cultural and social factors that may underlie these regional differences is needed. Several factors were not measured or accounted for in the current study that may influence or help explain differences in awareness and attitudes towards genetic testing. Cultural beliefs, attitudes, and behaviors, including spiritual faith and religious practices, have been associated with openness and response to genetic testing for disease (Hughes et al. 2003; Lannin et al. 1998; Schwartz et al. 2000). Other belief systems such as temporal orientation and communalism have also been associated with likelihood to seek genetic testing for disease (Halbert et al. 2005; Hughes et al. 2003; Lukwago et al. 2003). In addition, experiences are shaped differently in different locations with different histories of race and class. For example, what it is to be black in Norman, OK-especially as that might relate to entangled histories with Native American tribes-may be quite different from what it is to be black in Harlem, NY or Washington, DC. The case of Cincinnati further demonstrates the complexity of the relationship between history/experience and attitudes. Future studies will benefit from increased sociological rigor and attention to the individual and collective beliefs, values, and experiences that potentially mediate the observed regional differences shown in the current study. 
Understanding the covariances and interactions among these socioenvironmental factors and the genetics that underlie health outcomes will facilitate the genetic counseling process associated with individual genetic testing as well as our ability to understand and improve individual and group health (Gravlee et al. 2009). As demonstrated by our study, further exploration of the attitudes toward health-related genetic testing versus ancestry testing is warranted.

Second, there is a need for additional general population studies of awareness and attitudes regarding genetic testing, particularly ancestry testing. Studies utilizing convenient samples, such as reported here, can be informative, but limit the generalizability of findings. The most useful study designs are likely to be those that enable us to also gather perspectives from persons with little or no interest in the testing under investigation.

Third, our results suggest that research findings from single sites should be interpreted with caution. Few studies have included samples from multiple regions across the US, a factor that may have contributed to the inconsistencies in previous findings. More regionally diverse samples are needed to fully explore the differences that geography makes in test takers' awareness and attitudes including differences in ethnic and socioeconomic identity formation across space and time. Such studies could prove invaluable in informing decisions about the development of state-wide and perhaps national policies regarding genetic testing. Further, the current study is differentiated from other similar studies in that our survey included several open-ended items, which potentially gives the results added depth and breadth. Standardization of surveying methods for general social awareness and attitudes related to science and medicine will help increase our ability to collect and compare data nationally and internationally.

Attitudes towards genetic testing result from a complex contribution of beliefs and perspectives that are constantly in flux and ever changing (Condit 2001). These changing tides may be less due to polar ethnic influences than once thought. Rather, factors local to the individual such as regional history and culture may be more influential than social identity.

Acknowledgments We thank the study participants and the community-based organizations that facilitated the forums. We are also grateful to Jill Cooper for technical assistance and to Jennifer Wagner and our anonymous reviewers for providing comments on earlier versions of this manuscript. This work was funded in part by Grant Number P20HG03373 from the National Human Genome Research Institute, National Institutes of Health.

Conflict of interest statement Dr. Kittles has financial interests in ancestry testing companies and/or products. The other authors have no conflicts of interest.
Open Access This article is distributed under the terms of the Creative Commons Attribution Noncommercial License which permits any noncommercial use, distribution, and reproduction in any medium, provided the original author(s) and source are credited.

\section{References}

Armstrong K, Micco E, Carney A, Stopfer J, Putt M (2005) Racial differences in the use of BRCA1/2 testing among women with a family history of breast or ovarian cancer. JAMA 293(14):1729_ 1736

Bandelt HJ, Yao YG, Richards MB, Salas A (2008) The brave new era of human genetic testing. Bioessays 30(11-12):1246-1251

Bolnick DA, Fullwiley D, Duster T, Cooper RS, Fujimura JH, Kahn J et al (2007) Genetics. The science and business of genetic ancestry testing. Science 318(5849):399-400

Bowen DJ, Harris J, Jorgensen CM, Myers MF, Kuniyuki A (2009) Socioeconomic Influences on the effects of a genetic testing direct-to-consumer marketing campaign. Public Health Genomics 13(3):131-142

Case AP, Ramadhani TA, Canfield MA, Wicklund CA (2007) Awareness and attitudes regarding prenatal testing among Texas women of childbearing age. J Genet Couns 16(5):655-661

Caulfield T, Fullerton S, Ali-Khan S, Arbour L, Burchard E, Cooper $\mathrm{R}$ et al (2009) Race and ancestry in biomedical research: exploring the challenges. Genome Med 1(1):8

Chen LS, Goodson P (2007) Factors affecting decisions to accept or decline cystic fibrosis carrier testing/screening: a theory-guided systematic review. Genet Med 9(7):442-450

Collins FS, McKusick VA (2001) Implications of the Human Genome Project for medical science. JAMA 285(5):540-544

Condit C (2001) What is 'public opinion' about genetics? Nat Rev Genet 2(10):811-815

Corbie-Smith G, Thomas SB, Williams MV, Moody-Ayers S (1999) Attitudes and beliefs of African Americans toward participation in medical research. J Gen Intern Med 14(9):537-546

Duster T (2006) Lessons from history: why race and ethnicity have played a major role in biomedical research. J Law Med Ethics 34(3):487-496, 479

Duster T (2009) Ancestry testing and DNA: Uses, limits—and caveat emptor. Genewatch 22(3-4):16-17

Einsiedel EF (2000) Cloning and its discontents-a Canadian perspective. Nat Biotechnol 18(9):943-944

Elliott C, Brodwin P (2002) Identity and genetic ancestry tracing. BMJ 325(7378):1469-1471

Fairchild AL, Bayer R (1999) Uses and abuses of Tuskegee. Science 284(5416):919-921

Gamble VN (1993) A legacy of distrust: African Americans and medical research. Am J Prev Med 9(6 Suppl):35-38

Gamble VN (1997) Under the shadow of Tuskegee: African Americans and health care. Am J Public Health 87(11):17731778

Gaskell G, Bauer MW, Durant J, Allum NC (1999) Worlds apart? The reception of genetically modified foods in Europe and the U.S. Science 285(5426):384-387

Gaskell G, Allum N, Bauer M, Durant J, Allansdottir A, Bonfadelli H et al (2000) Biotechnology and the European public. Nat Biotechnol 18(9):935-938

Ge D, Fellay J, Thompson AJ, Simon JS, Shianna KV, Urban TJ et al (2009) Genetic variation in IL28B predicts hepatitis C treatmentinduced viral clearance. Nature 461(7262):399-401

Gravlee CC, Non AL, Mulligan CJ (2009) Genetic ancestry, social classification, and racial inequalities in blood pressure in Southeastern Puerto Rico. PLoS One 4(9):e6821 
Guttmacher AE, Collins FS (2005) Realizing the promise of genomics in biomedical research. JAMA 294(11):1399-1402

Halbert CH, Kessler LJ, Mitchell E (2005) Genetic testing for inherited breast cancer risk in African Americans. Cancer Invest 23(4):285-295

Halbert CH, Kessler L, Stopfer JE, Domchek S, Wileyto EP (2006) Low rates of acceptance of BRCA1 and BRCA2 test results among African American women at increased risk for hereditary breast-ovarian cancer. Genet Med 8(9):576-582

Halbert CH, Barg FK, Weathers B, Delmoor E, Coyne J, Wileyto EP et al (2007) Differences in cultural beliefs and values among African American and European American men with prostate cancer. Cancer Control 14(3):277-284

Hensley Alford S, McBride CM, Reid RJ, Larson EB, Baxevanis AD, Brody LC (2010) Participation in Genetic Testing Research Varies by Social Group. Public Health Genomics [Epub ahead of print]

Howard HC, Borry P (2009) Personal genome testing: do you know what you are buying? Am J Bioeth 9(6-7):11-13

Hudson K, Javitt G, Burke W, Byers P (2007) ASHG Statement* on direct-to-consumer genetic testing in the United States. Obstet Gynecol 110(6):1392-1395

Hughes C, Gomez-Caminero A, Benkendorf J, Kerner J, Isaacs C, Barter J et al (1997) Ethnic differences in knowledge and attitudes about BRCA1 testing in women at increased risk. Patient Educ Couns 32(1-2):51-62

Hughes C, Fasaye GA, LaSalle VH, Finch C (2003) Sociocultural influences on participation in genetic risk assessment and testing among African American women. Patient Educ Couns 51(2): $107-114$

International HapMap Consortium (2004) Integrating ethics and science in the International HapMap Project. Nat Rev Genet 5(6):467-475

Kaphingst KA, McBride CM (2010) Patient responses to genetic information: studies of patients with hereditary cancer syndromes identify issues for use of genetic testing in nephrology practice. Semin Nephrol 30(2):203-214

Khoury MJ, Mcbride CM, Schully SD, Ioannidis JPA, Feero WG, Janssens ACJW et al (2009) The Scientific Foundation for Personal Genomics: recommendations from a National Institutes of Health-Centers for Disease Control and Prevention Multidisciplinary Workshop. Genet Med 11(8):559-567

King KA (2008) Sustaining linguistic diversity: endangered and minority languages and language varieties. Georgetown University Press, Washington, DC

Lakeman P, Plass AM, Henneman L, Bezemer PD, Cornel MC, ten Kate LP (2008) Three-month follow-up of Western and nonWestern participants in a study on preconceptional ancestrybased carrier couple screening for cystic fibrosis and hemoglobinopathies in the Netherlands. Genet Med 10(11):820-830

Lakeman P, Plass AM, Henneman L, Bezemer PD, Cornel MC, ten Kate LP (2009) Preconceptional ancestry-based carrier couple screening for cystic fibrosis and haemoglobinopathies: what determines the intention to participate or not and actual participation? Eur J Hum Genet 17(8):999-1009

Lannin DR, Mathews HF, Mitchell J, Swanson MS, Swanson FH, Edwards MS (1998) Influence of socioeconomic and cultural factors on racial differences in late-stage presentation of breast cancer. JAMA 279(22):1801-1807

Lee SS, Crawley L (2009) Research 2.0: social networking and directto-consumer (DTC) genomics. Am J Bioeth 9(6-7):35-44

Lee SS, Bolnick D, Duster T, Ossorio P, TallBear K (2009) The illusive gold standard in genetic ancestry testing. Science 325(5936):38-39

Lerman C, Hughes C, Benkendorf JL, Biesecker B, Kerner J, Willison $\mathbf{J}$ et al (1999) Racial differences in testing motivation and psychological distress following pretest education for BRCA1 gene testing. Cancer Epidemiol Biomark Prev 8(4 Pt 2):361-367

Lukwago SN, Kreuter MW, Holt CL, Steger-May K, Bucholtz DC, Skinner CS (2003) Sociocultural correlates of breast cancer knowledge and screening in urban African American women. Am J Public Health 93(8):1271-1274

MacNew HG, Rudolph R, Brower ST, Beck AN, Meister EA (2010) Assessing the knowledge and attitudes regarding genetic testing for breast cancer risk in our region of southeastern Georgia. Breast J 16(2):189-192

May K (1996) African Americans and Native Americans in the Creek and Cherokee Nations, 1830s to 1920s: collision and collusion. Garland Pub, New York

McCabe LL, McCabe ER (2004) Direct-to-consumer genetic testing: access and marketing. Genet Med 6(1):58-59

McGuire AL, Diaz CM, Wang T, Hilsenbeck SG (2009) Social networkers' attitudes toward direct-to-consumer personal genome testing. Am J Bioeth 9(6-7):3-10

Nelson A (2008) Bio science: genetic genealogy testing and the pursuit of african ancestry. Soc Stud Sci 38(5):759-783

Palmer CG, Martinez A, Fox M, Sininger Y, Grody WW, Schimmenti LA (2008) Ethnic differences in parental perceptions of genetic testing for deaf infants. J Genet Couns 17(1):129-138

Peters N, Rose A, Armstrong K (2004) The association between race and attitudes about predictive genetic testing. Cancer Epidemiol Biomark Prev 13(3):361-365

Power TE, Adams PC, Barton JC, Acton RT, Howe E, Palla S et al (2007) Psychosocial impact of genetic testing for hemochromatosis in the HEIRS Study: a comparison of participants recruited in Canada and in the United States. Genet Test 11(1):55-64

Prainsack B, Reardon J, Hindmarsh R, Gottweis H, Naue U, Lunshof JE (2008) Personal genomes: misdirected precaution. Nature 456(7218):34-35

Priest SH (2000) US public opinion divided over biotechnology? Nat Biotechnol 18(9):939-942

Schwartz MD, Hughes C, Roth J, Main D, Peshkin BN, Isaacs C et al (2000) Spiritual faith and genetic testing decisions among highrisk breast cancer probands. Cancer Epidemiol Biomark Prev 9(4):381-385

Scott AJ (2000) The cultural economy of cities: essays on the geography of image-producing industries. SAGE Publications, London

Shriver MD, Kittles RA (2004) Genetic ancestry and the search for personalized genetic histories. Nat Rev Genet 5(8):611-618

Singer E, Antonucci T, Van Hoewyk J (2004) Racial and ethnic variations in knowledge and attitudes about genetic testing. Genet Test 8(1):31-43

Suther S, Kiros GE (2009) Barriers to the use of genetic testing: a study of racial and ethnic disparities. Genet Med 11(9):655-662

TallBear K (2007) Narratives of race and indigeneity in the Genographic Project. J Law Med Ethics 35(3):412-424

Taylor Q (1998) In search of the racial frontier: African Americans in the American West, 1528-1990, 1st edn. Norton, New York

Thompson HS, Valdimarsdottir HB, Jandorf L, Redd W (2003) Perceived disadvantages and concerns about abuses of genetic testing for cancer risk: differences across African American, Latina and Caucasian women. Patient Educ Couns 51(3):217-227

United States Bureau of the Census, Geography Division (Cartographer) (2002) American Indians and Alaska Natives in the United States [2 maps on 1 sheet]

United States. National Park Service, and Parks and History Association (Cartographer) (1987) City of the Constitution, Washington, DC [1 map]

Varcoe C, Browne AJ, Wong S, Smye VL (2009) Harms and benefits: collecting ethnicity data in a clinical context. Soc Sci Med 68(9):1659-1666 
Wagner JK (2010) Interpreting the implications of DNA ancestry tests. Perspect Biol Med 53(2):231-248

Wilde A, Meiser B, Mitchell PB, Schofield PR (2010) Public interest in predictive genetic testing, including direct-to-consumer testing, for susceptibility to major depression: preliminary findings. Eur J Hum Genet 18(1):47-51

Winston C, Kittles R (2005) Inferring African ancestry of African Americans. In: Turner $\mathrm{T}$ (ed) Biological anthropology and ethics. SUNY Press, New York

Wong ML, Chia KS, Wee S, Chia SE, Lee J, Koh WP et al (2004) Concerns over participation in genetic research among MalayMuslims, Chinese and Indians in Singapore: a focus group study. Community Genet 7(1):44-54
Zeigler-Johnson CM, Spangler E, Jalloh M, Gueye SM, Rennert H, Rebbeck TR (2008) Genetic susceptibility to prostate cancer in men of African descent: implications for global disparities in incidence and outcomes. Can J Urol 15(1):3872-3882

Zhang W, Duan S, Bleibel WK, Wisel SA, Huang RS, Wu X et al (2009) Identification of common genetic variants that account for transcript isoform variation between human populations. Hum Genet 125(1):81-93

Zhu X, Luke A, Cooper RS, Quertermous T, Hanis C, Mosley T et al (2005) Admixture mapping for hypertension loci with genomescan markers. Nat Genet 37(2):177-181 